\title{
EFEITO DA ADIÇÃO DE ÁCIDOS GRAXOS EM FILMES À BASE DE PECTINA ${ }^{1}$
}

\author{
Juliana A. BATISTA², Patrícia S. TANADA-PALMU², Carlos R. F. GROSSO²
}

\section{RESUMO}

Os objetivos deste trabalho foram desenvolver filmes à base de pectina de baixo teor de esterificação, amidada, com adição dos ácidos graxos láurico (AL), palmítico (AP) e esteárico (AE) e caracterizá-los quanto às propriedades de permeabilidade ao vapor de água (PVA) e ao oxigênio, propriedades mecânicas (tensão de ruptura e elongação), solubilidade em água e opacidade, além de observar a morfologia da superfície dos filmes utilizando microscopia eletrônica de varredura (MEV). A adição de 12 e $18 \%$ dos ácidos promoveu aumento da PVA e da elongação e redução da tensão de ruptura, em relação aos filmes com $6 \%$ de ácido graxo. Todos os filmes apresentaram-se $100 \%$ solúveis em água e mais opacos quando os ácidos graxos foram adicionados. A partir da MEV, foi observado que os ácidos graxos não se incorporaram à matriz filmogênica.

Palavras-chave: biofilmes, permeabilidade, solubilidade em água, microscopia eletrônica.

\section{SUMMARY}

THE EFFECT OF ADDITION OF FATTY ACIDS ON PECTIN FILMS. The purposes of this research were to develop and characterize composite biofilms produced with low methoxyl amidated pectin plus lauric, palmitic and stearic acids. Water vapor permeability, oxigen permeability, mechanical properties (tensile strength and elongation), water solubility, opacity and, surface morphology were evaluated. The increase of fatty acids addition to 12 and $18 \%$ resulted in an increase in water vapor permeability and elongation and a decrease in tensile strength compared to the level of $6 \%$ of fatty acids. All formulations produced films showing $100 \%$ water solubility. As observed by scanning electronic microscopy the fatty acids were not homogeneously incorporated on the filmogenic matrices. Keywords: biofilms, permeability, water solubility, electronic microscopy.

\section{1 - INTRODUÇÃO}

Considerável interesse tem sido demonstrado no desenvolvimento e caracterização de biofilmes devido ao potencial de aplicação destes produtos nos setores alimentício, agrícola e também pela questão da biodegradabilidade. Os biofilmes podem ser utilizados para controlar a migração de água de um sistema alimentício, a permeabilidade ao oxigênio, ao dióxido de carbono, eventualmente a migração lipídica e, ainda, podem conter antioxidantes, antimicrobianos e aditivos, os quais visam retardar a taxa de deterioração quando utilizados no envolvimento de um produto alimentício [13, 23, 27]. Quando aplicados como coberturas em sementes agrícolas, os biofilmes podem regular a passagem de água e oxigênio necessários à germinação e, dependendo de seu caráter (hidrofílico ou hidrofóbico), também podem atuar como carreadores de nutrientes ou substâncias químicas e biológicas, as quais podem auxiliar no desenvolvimento das plantas e ter impacto reduzido sobre o meio ambiente $[8,14,26]$.

Os biofilmes geralmente são elaborados a partir de proteínas, polissacarídeos, lipídios ou da combinação destes compostos. Filmes constituídos por proteínas e polissacarídeos normalmente apresentam alta resistência mecânica e permeabilidade seletiva a gases, mas são sensíveis à umidade, sendo que aqueles elaborados apenas com lipídios são resistentes à passagem de água, mas apresentam-se opacos e quebradiços [18, 30, 32, 41]. Dessa forma, a combinação de compostos pode resultar em melhores propriedades funcionais dos filmes.

${ }^{1}$ Recebido para publicação em 21/02/2005. Aceito para publicação em 28/09/2005 (001486).

${ }^{2}$ Departamento de Alimentos e Nutrição, Faculdade de Engenharia de Alimentos, UNICAMP, Caixa Postal: 6121.E-mail: grosso@fea.unicamp.br.
YANG \& PAULSON [41] observaram que a adição de ceras, ácidos graxos saturados de cadeia longa e álcoois graxos apresentou-se efetiva na diminuição da PVA de filmes à base de gelana. Diminuição da PVA e da tensão de ruptura (TR) também foi observada em filmes de glúten adicionados dos ácidos esteárico, palmítico e da cera de abelha, quando comparados aos mesmos filmes sem a adição de lipídios [37]. As características de um filme adicionado destes compostos dependem da ligação de lipídios à matriz polimérica [29, 11]. WONG et al. [39] verificaram microestrutura uniforme em filmes de quitosana adicionados de ácido láurico, sendo que nos filmes desse mesmo polissacarídeo contendo ácido palmítico, uma matriz heterogênea foi observada.

Entre os diversos polissacarídeos que podem originar uma matriz filmogênica encontra-se a pectina, polissacarídeo solúvel em água e geralmente obtido a partir da casca e polpa de frutas cítricas ou maçã, ou ainda, de sementes de girassol e polpa de beterraba [38]. A geleificação das pectinas de baixo grau de esterificação resulta da ligação iônica através de pontes de cálcio entre dois grupos carboxílicos pertencentes a cadeias diferentes, próximas fisicamente [6].

Em produtos semiprontos destinados ao preparo por cocção, torna-se útil o uso de filmes comestíveis que se desintegrem ao entrar em contato com a água [20]. Por outro lado, muitas aplicações dos filmes em alimentos têm por objetivo reduzir a transferência de água do meio externo para o produto, aumentando assim sua integridade [31]. FISHMAN \& COFFIN [16] ao estudarem a solubilidade dos filmes a base da mistura de pectina e polivinil álcool verificaram que a 30 e $50^{\circ} \mathrm{C}$ apenas os filmes contendo $30 \%$ 
ou menos de polivinil álcool na mistura foram solúveis em água. Em relação à tensão de ruptura, MARINELLO et al. [25] encontraram um valor quase duas vezes maior para os filmes provenientes da mistura pectina e farinha de soja adicionada da transglutaminase (12,4 MPa), em relação aos filmes preparados na ausência dessa enzima (6,8 MPa).

Os objetivos deste trabalho foram desenvolver filmes à base de pectina (PEC) com adição dos ácidos graxos láurico (AL), palmítico (AP) e esteárico (AE) e caracterizá-los quanto às propriedades de barreira à água e ao oxigênio, propriedades mecânicas, solubilidade em água, opacidade e avaliar a morfologia de superfície dos mesmos.

\section{2 - MATERIAL E MÉTODOS}

Pectina de baixo teor de esterificação (30\%), amidada (18\%), não padronizada e obtida a partir de frutas cítricas foi cedida pela CPKelco Brasil S/A (lote no. 2146419-35), cloreto de cálcio (Merck), triacetina cedida pela Rhodia e ácidos láurico $(\mathrm{AL})$, esteárico $(\mathrm{AE})$ e palmítico (AP) (Vetec).

Inicialmente, foram realizados alguns ensaios variando as concentrações de PEC de 1 a $5 \%(\mathrm{p} / \mathrm{v})$ e cloreto de cálcio $\left(\mathrm{CaCl}_{2}\right)$ de 0,02 a $0,16 \%(\mathrm{p} / \mathrm{v})$, visando conhecer o comportamento das soluções obtidas e dos filmes formados em relação às características visuais, solubilidade em água e resistência mecânica. Os filmes foram elaborados da seguinte maneira: a solução de PEC foi mantida em aquecimento a $60^{\circ} \mathrm{C}$ com agitação magnética moderada até completa solubilização. Em seguida, foi adicionada a respectiva solução de $\mathrm{CaCl}_{2}$, mantendo-se a agitação e aquecimento por $5 \mathrm{~min}$. Alíquotas de $55 \mathrm{~mL}$ dessa solução foram pipetadas em placas de plexiglass de $14 \mathrm{~cm}$ de diâmetro e mantidas à temperatura ambiente $\left(25^{\circ} \mathrm{C}\right)$ durante $38 \mathrm{~h}$ para secagem. Filmes sem adição de $\mathrm{CaCl}_{2}$ também foram elaborados.

\section{1 - Preparo das soluções filmogênicas à base de pectina (PEC) e ácidos graxos}

A solução de PEC $2 \%(\mathrm{p} / \mathrm{v})$ foi mantida sob aquecimento a $60^{\circ} \mathrm{C}$ com agitação magnética moderada até completa solubilização do material. Triacetina representando $1 \%(\mathrm{p} / \mathrm{p})$ em relação ao peso da pectina, foi adicionada à solução, mantendo o aquecimento e a agitação magnética durante $5 \mathrm{~min}$. Em seguida, $6 \%$ de AL, em relação ao peso de pectina, foram solubilizados em placa a $80^{\circ} \mathrm{C}$ e adicionados à solução de PEC. O mesmo procedimento foi repetido para a adição de 12 e 18\% de AL, assim como para os demais ácidos em estudo. A adição de 6, 12 e 18\% (p/p) da mistura (mis) de AL, AP e AE na proporção 1:1:1 (p/p/p) na solução de pectina também foi previamente solubilizada em placa a $80^{\circ} \mathrm{C}$, seguindo o procedimento descrito anteriormente.

\section{2 - Elaboração dos filmes}

Alíquotas de $38 \mathrm{~mL}$ das soluções elaboradas foram pipetadas e distribuídas em placas plexiglass de $14 \mathrm{~cm}$ de diâmetro. O material foi mantido à temperatura am- biente $\left(25^{\circ} \mathrm{C}\right)$ sobre superfície nivelada durante $33 \mathrm{~h}$ para secagem. Após esse período, os filmes foram retirados das placas e armazenados em dessecadores contendo nitrato de magnésio, a $25^{\circ} \mathrm{C}$ e $52 \pm 2 \%$ de umidade relativa (UR), durante $48 \mathrm{~h}$ antes do início das análises.

\section{3 - Caracterização dos filmes}

\subsection{1 - Espessura}

A espessura foi obtida pela média dos valores de dez pontos aleatórios em diferentes segmentos do filme, utilizando-se um micrômetro digital (Model MDC-25M, Mitutoyo, MFG, Japan, resolução 0,001 mm).

\subsection{2 - Permeabilidade ao vapor de água (PVA)}

A PVA dos filmes foi determinada gravimetricamente a $25^{\circ} \mathrm{C}$ utilizando o método padrão E-96-95 da ASTM [4] modificado, e foi expressa em gmm $/ \mathrm{m}^{2} \mathrm{~d} . \mathrm{kPa}$. As amostras de cada filme foram seladas com parafina em células de permeação de alumínio contendo cloreto de cálcio. Essas células foram acondicionadas em dessecadores mantendo-se a temperatura de $25^{\circ} \mathrm{C}$ e $75 \%$ UR. A partir do ganho de peso do cloreto de cálcio, medido em intervalos de $24 \mathrm{~h}$, foi possível determinar a permeabilidade ao vapor de água através dos filmes. As análises foram realizadas em triplicata.

\subsection{3 - Propriedades mecânicas}

As análises da tensão de ruptura (TR) e porcentagem de elongação (ELON) foram realizadas com o aparelho texturômetro TA-XT2 (Stable Micro System, Surrey, UK), seguindo o método padrão ASTM D-882 [5], com separação inicial das garras de $50 \mathrm{~mm}$ e velocidade do probe de $1 \mathrm{~mm} / \mathrm{s}$. Seis a dez amostras de cada filme foram recortadas $(100 \mathrm{~mm}$ de comprimento e $25 \mathrm{~mm}$ de largura) e fixadas, uma a cada vez, no texturômetro após serem condicionadas em dessecadores a $25^{\circ} \mathrm{C}$ e $52 \pm 2 \%$ de umidade relativa (UR), durante $48 \mathrm{~h}$ antes do início das análises.

\subsection{4 - Solubilidade em água}

A análise de solubilidade em água foi realizada em triplicata, seguindo o método proposto por GONTARD et al. [19]. Filmes com $2 \mathrm{~cm}$ de diâmetro foram imersos em $50 \mathrm{~mL}$ de água destilada, mantidos sob agitação lenta e periódica por $24 \mathrm{~h}$ à temperatura ambiente $\left(25^{\circ} \mathrm{C}\right) \mathrm{em}$ banho-maria. Os fragmentos de filme restantes foram então retirados do banho e secos em estufa $\left(105^{\circ} \mathrm{C}, 24 \mathrm{~h}\right)$ para determinação da massa seca final, e comparados à massa seca inicial.

\subsection{5 - Permeabilidade ao oxigênio}

A taxa de transmissão de oxigênio foi determinada utilizando um aparelho OX-TRAN 2/20 (Mocon, Inc.) a $25^{\circ} \mathrm{C}$ a partir do método padrão ASTM D-3985-81 modificado [3]. A área exposta dos filmes destinada à passagem dos gases foi fixada em suportes vazados de alumínio e a permeabilidade ao oxigênio foi determinada em duplicata à temperatura de $25^{\circ} \mathrm{C}$. 
A diferença de pressão através do filme corresponde à pressão atmosférica (101,3 kPa). As amostras do filme, no instrumento de medida, foram submetidas a $100 \%$ de gás oxigênio de um lado e de um gás de arraste contendo $98 \%$ de nitrogênio e $2 \%$ de hidrogênio do outro lado. Os filmes de PEC adicionados de ácidos graxos utilizados para essa caracterização foram selecionados quanto à menor PVA e maior TR.

\subsection{6 - Opacidade dos filmes}

A opacidade dos filmes foi determinada utilizando-se o colorímetro Hunterlab (Colorquest II, Faifax, USA), seguindo o método HUNTERLAB [21]. Assim, a opacidade (Y) foi calculada como a relação entre a opacidade do filme colocado sobre o padrão preto (Yp) e a opacidade do filme colocado sobre o padrão branco $(\mathrm{Yb})$. O cálculo da opacidade, em porcentagem, foi realizado automaticamente no computador associado ao colorímetro pelo programa Universal Software 3.2 [21].

Todos os filmes selecionados para a realização da análise de opacidade (filmes de PEC contendo 6\% de ácidos graxos) foram comparados com o filme comercial de policloreto de vinila (PVC).

\subsection{7 - Microscopia eletrônica de varredura (MEV)}

Os filmes foram mantidos em dessecadores contendo sílica gel à temperatura ambiente $\left(25^{\circ} \mathrm{C}\right)$ durante sete dias antes da análise microscópica. Depois, foram fragmentados e amostras de cada um deles foram fixadas em suporte de alumínio (stubs), com fita condutiva de cobre. As amostras foram recobertas com ouro (SPUTTER COATER BALZERS_SCD 050, Baltec, Lichtenstein) a $25^{\circ} \mathrm{C}$ e pressão de 2 x $10-5$ Torr por $180 \mathrm{~s} \mathrm{e}$, em seguida, observadas em microscópio eletrônico de varredura (JEOL SCANNING MICROSCOPE -JMS-5800LV) a 10 kV em sala climatizada $\left(18^{\circ} \mathrm{C}\right)$. Os aumentos utilizados na observação microscópica se encontram nas micrografias onde a barra indicativa de aumento corresponde a $100 \mu \mathrm{m}$.

\section{4 - Análise estatística}

As análises de variância (ANOVA) foram realizadas utilizando-se o programa Statistica ${ }^{\circledR}$ (Statsoft, USA). As diferenças significativas entre as médias foram identificadas através do teste de Tukey $(\mathrm{p}<0,05)$.

\section{3 - RESULTADOS E DISCUSSÃo}

\section{1 - Influência da adição de cálcio à solução filmogênica de pectina}

As variações dos teores de $\mathrm{PEC} \mathrm{e} \mathrm{CaCl}_{2}$ resultaram em situações que incluíam estado sol, gel e ainda promoveram sinérese em determinados pontos (Figura 1), sendo essas duas últimas inviáveis para produção de filmes devido à distribuição não uniforme nas placas. As soluções de PEC 3, 4 e $5 \%$ contendo $0,08 \%$ de $\mathrm{CaCl}_{2}$ apresentaram-se solúveis, porém mais viscosas que aquelas contendo 0,06\%, o que dificultava sua distribuição nas placas, sendo o mesmo motivo válido para a solução de PEC $5 \%$ adicionada de concentrações entre 0,02 e 0,08\% de $\mathrm{CaCl}_{2}$.

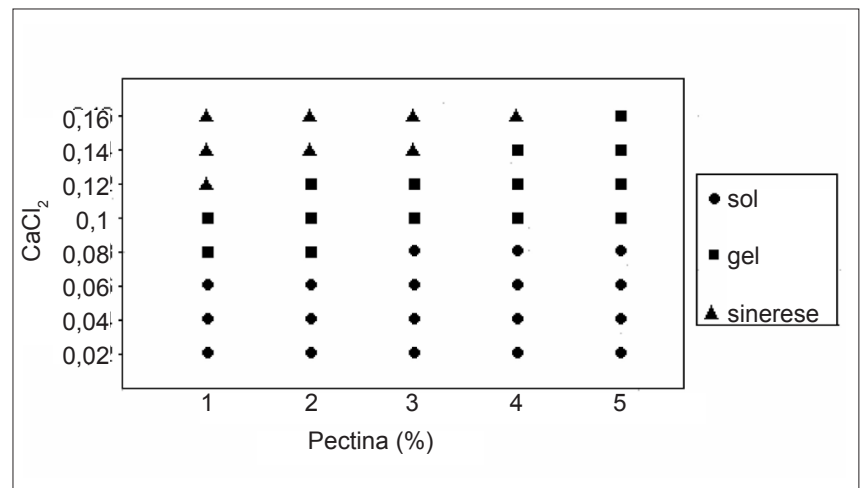

FIGURA 1 - Diagrama de fases das diferentes combinações de pectina (PEC) e cloreto de cálcio $\left(\mathrm{CaCl}_{2}\right)$

Os filmes formados com teores de PEC abaixo de $4 \%$ (adicionados de $\mathrm{CaCl}_{2}$ 0,02 a 0,06\%) foram descartados, pois se apresentaram muito frágeis, difíceis de serem retirados das placas plexiglass e finos quando comparados visualmente aos filmes elaborados a partir da mesma alíquota (55 mL), com 4\% PEC e 0,06\% $\mathrm{CaCl}_{2}$.

A caracterização dos filmes de PEC quanto às propriedades de barreira à água (PVA) e resistência mecânica (TR e ELON) não apresentou diferença significativa $(\mathrm{p}<0,05)$ quando adicionados ou não de cloreto de cálcio (Tabela 1). GALIETTA et al. [17] também verificaram que a adição de baixa concentração de $\mathrm{CaCl}_{2}$ na formulação dos filmes de proteína do soro de leite não afetou significativamente as propriedades funcionais dos mesmos. A formação de ligações iônicas nos filmes adicionados de $\mathrm{CaCl}_{2}$ provavelmente não foi suficiente para promover um aumento das propriedades mecânicas dos filmes e para promover um abaixamento da solubilidade desses filmes [17].

\section{2 - Espessura}

Após o estudo inicial para ajuste da relação pectina/ cálcio, todos os outros filmes foram elaborados de forma a apresentarem espessura média de 0,066 $\pm 0,005 \mathrm{~mm}$, requerendo ajustes de volume para cada formulação. A uniformidade da espessura dos filmes é importante, pois funciona como base para cálculo de várias propriedades funcionais dos filmes [40].

TABELA 1 - Caracterização dos filmes de pectina (PEC) a $25^{\circ} \mathrm{C}$, na presença ou não do cloreto de cálcio $(\mathrm{CaCl} 2)$, quanto à espessura, permeabilidade ao vapor de água (PVA), resistência à tração (TR) e elongação (ELON)

\begin{tabular}{|c|c|c|c|c|}
\hline Filmes & Espessura $(\mathrm{mm})^{*}$ & PVA (g.mm/m²d.kPa)* & $\operatorname{TR}(\mathrm{MPa})^{*}$ & $\operatorname{ELON}(\%)^{*}$ \\
\hline PEC com $\mathrm{CaCl}_{2}$ & $0,066 \pm 0,004$ & $7,21 \pm 0,64^{a}$ & $91,11 \pm 2,67^{a}$ & $2,93 \pm 0,41^{a}$ \\
\hline PEC sem $\mathrm{CaCl}_{2}$ & $0,065 \pm 0,003$ & $6,80 \pm 0,12^{\mathrm{a}}$ & $90,54 \pm 2,64^{a}$ & $2,90 \pm 1,20^{a}$ \\
\hline
\end{tabular}

* Média e desvio padrão de repetições. ${ }^{a}$ Letras sobrescritas iguais na mesma coluna não diferem significativamente em nível de $\mathrm{p}<0,05$, de acordo o teste de Tukey. 


\section{3 - Permeabilidade ao vapor de água}

Os filmes de PEC adicionados de AL, AP, AE e da mistura destes ácidos graxos (1AL:1AP:1AE) apresentaram aumento significativo $(\mathrm{p}<0,05)$ da permeabilidade ao vapor de água (Tabela 2) quando o teor de ácidos graxos foi aumentado de 6 para 18\%. Embora os ácidos graxos se apresentem como hidrofóbicos, eles contêm grupos carboxílicos altamente polares que podem interagir com moléculas de água e, conseqüentemente, facilitar a transferência de umidade através do filme [41]. RHIM et al. [33] atribuíram o aumento da permeabilidade nos filmes à base de isolado protéico de soja com $10 \%$ de ácido esteárico e ácido oléico à parte hidrofílica do lipídio.

Mediante o aumento de PVA em filmes de glúten adicionados de lipídios, GONTARD et al. [19] sugeriram que, se os componentes lipídicos, geralmente esféricos, não forem capazes de se associar com a cadeia de proteína, a estrutura da matriz pode ser rompida, resultando em perda global das propriedades de barreira à umidade do filme. A organização do complexo proteína-lipídios e a interação entre esses dois componentes parece ser um fator crítico na permeabilidade dos filmes [19].

O aumento da PVA observado com o aumento dos ácidos graxos adicionados (Tabela 2), possivelmente pode ter ocorrido devido à desestabilização da matriz filmogênica de PEC, permitindo assim que facilmente houvesse a migração de vapor de água. Por outro lado, YANG \& PAULSON [41] verificaram que os filmes de gelana elaborados com a mistura de ácido esteárico e palmítico ( $1: 1$ ) e os de gelana com adição de cera de abelha apresentaram redução de $20 \%$ e $53 \%$ na PVA, respectivamente, em relação aos mesmos filmes elaborados sem o acréscimo de lipídio. Esses autores discutiram a redução de PVA baseando-se no aspecto microestrutural observado na matriz filmogênica. Quando há incorporação do material lipídico à matriz, o espaço livre para passagem de água acaba sendo reduzido, o que diminui a PVA.

TABELA 2 - Permeabilidade ao vapor de água (PVA) dos filmes compostos de PEC, triacetina e ácidos graxos

\begin{tabular}{rc}
\hline Filmes $^{*}$ & PVA $\left(\mathbf{g m m} / \mathbf{m}^{2} \mathbf{d . k P a}\right)^{* *}$ \\
\hline PEC/AL $6 \%$ & $6,54 \pm 0,63^{\mathrm{d}}$ \\
$12 \%$ & $8,06 \pm 0,46^{\mathrm{c}}$ \\
$18 \%$ & $6,75 \pm 0,50^{\mathrm{d}}$ \\
\hline PEC/AP $6 \%$ & $5,79 \pm 0,24^{\mathrm{e}}$ \\
$12 \%$ & $5,41 \pm 0,20^{\text {ef }}$ \\
$18 \%$ & $6,76 \pm 0,15^{\mathrm{d}}$ \\
\hline PEC/AE $6 \%$ & $5,03 \pm 0,64^{\mathrm{f}}$ \\
$12 \%$ & $5,89 \pm 0,56^{\mathrm{e}}$ \\
$18 \%$ & $6,91 \pm 0,40^{\mathrm{d}}$ \\
\hline $12 \%$ & $8,48 \pm 0,27^{\mathrm{bc}}$ \\
$18 \%$ & $8,90 \pm 0,27^{\mathrm{ab}}$ \\
\hline PEC/mis $6 \%$ & $9,15 \pm 0,36^{\mathrm{a}}$ \\
\hline
\end{tabular}

*AL=ácido láurico; $\mathrm{AP}=$ ácido palmítico; $\mathrm{AE}=$ ácido esteárico; mis=mistura dos ácidos graxos; ** Média e desvio padrão de replicatas; ${ }^{\text {a-f }}$ médias com letras sobrescritas distintas são significativamente diferentes, de acordo com o teste de Tukey $(\mathrm{p}<0,05)$
Em relação ao tipo de ácido graxo utilizado nos filmes, os resultados revelaram que o aumento da cadeia carbônica dos ácidos graxos (AL-12 carbonos; AP-16 carbonos e AE18 carbonos) promoveu diminuição significativa $(\mathrm{p}<0,05)$ da permeabilidade sendo, neste caso, o ácido esteárico ( 18 carbonos), a 6\%, o que apresentou menor PVA (5,03 $\mathrm{gmm} / \mathrm{m}^{2} \mathrm{~d} . \mathrm{kPa}$ ). Os ácidos graxos de cadeia carbônica menor apresentam maior mobilidade [22], o que pode justificar a maior PVA observada para filmes contendo AL e AP em nível de $6 \%$ de adição. Um aumento significativo da PVA foi observado em todos os níveis de adição testados quando a mistura dos ácidos foi utilizada.

De acordo com AYRANCI \& TUNC [7], o teor de ácido esteárico acrescentado aos filmes de metilcelulose (MC) (5 g AE/100 g MC) promoveu redução da PVA de 40\% quando comparado com os filmes sem a presença de $\mathrm{AE}$, devido principalmente à hidrofobicidade do ácido graxo presente. PÉROVAL et al. [32] também constataram que a PVA dos filmes de arabinoxilana com ácido esteárico foi menor que a dos filmes com a adição de ácido palmítico, justificando o resultado em relação ao tamanho da cadeia carbônica dos ácidos graxos. Ao contrário desses resultados, WONG et al. [39] verificaram que nos filmes de quitosana, a adição de AL foi mais eficiente como barreira à água que nos filmes contendo AP, pois microscopicamente o primeiro filme apresentava uma matriz uniforme, o que dificultava a passagem de água através do mesmo.

Filmes à base de PEC adicionados de $1 \%$ de triacetina, sem adição de ácidos graxos, não foram elaborados para efeito comparativo neste trabalho, devido a não incorporação desse plastificante na matriz filmogênica quando somente a triacetina e o polissacarídeo eram utilizados. Após o procedimento de secagem, esses filmes apresentaram aspecto oleoso. Efeito semelhante foi observado por RHIM et al. [33] quando foram adicionados 20 e $30 \%$ de ácido oléico ao filme à base de isolado protéico de soja. Os autores relataram que a separação ocorrida na emulsão afetou as propriedades físicas dos filmes. ANKER, STADING \& HERMANSSON [2] também verificaram que a migração dos plastificantes (sorbitol ou glicerol) afetava as propriedades mecânicas de filmes à base de soro de leite.

\section{4 - Solubilidade em água}

A PEC é um polissacarídeo bastante hidrofílico e a adição de 6 e 18\% de ácidos graxos na formulação desses filmes não provocou diferença significativa quanto à solubilidade em água dos mesmos. Todos os filmes analisados apresentaram-se $100 \%$ solúveis. Normalmente, os polissacarídeos são altamente higroscópicos e se desintegram rapidamente em água [35]. Em determinadas aplicações, essa alta taxa de solubilidade pode ser desejável. Em geral, como a natureza dos ácidos graxos é hidrofóbica, eles tendem a diminuir a solubilidade do filme. No entanto, a não incorporação dos mesmos na matriz filmogênica pode ter contribuído para a maior exposição da matriz do hidrocolóide, facilitando a solubilização. 


\section{5 - Propriedades mecânicas dos filmes}

O aumento de 6 para 18\% de ácidos graxos nos filmes provocou redução significativa da TR (Tabela 3). Segundo CHEN [12], a adição de lipídios promove modificação na matriz filmogênica, o que resulta na diminuição da tensão de ruptura do filme. Esse efeito talvez tenha sido resultado da substituição parcial dos polímeros por lipídios na matriz do filme com diminuição de seu grau de estruturação pela falta de incorporação homogênea dos lipídios, assim como o ocorrido em filmes compostos de gelana e lipídios [41].

Em relação à propriedade de elongação, cada filme apresentou um comportamento específico frente à concentração e ao tipo de ácido graxo adicionado. A adição de $18 \%$ de AL nos filmes promoveu aumento significativo da ELON (de 1,8 para 3,7\%), sendo o mesmo verificado nos filmes adicionados de $\mathrm{AE}$ (de 3,5 a 6,0\%). Em oposição a esses resultados, o filme contendo $18 \%$ de AP apresentou redução significativa da ELON (de 2,8 a 1,8\%), conforme o teor de ácido foi aumentado de 6 para 18\% (Tabela 3).

SHELLHAMMER \& KROCHTA [34] observaram aumento na ELON dos filmes de proteína do soro do leite com o aumento da concentração de lipídios, o que, segundo os autores, foi causado pelo efeito plastificante do lipídio. Em contraposição, PÉROVAL et al. [32] observaram diminuição da ELON ao incorporar ácidos graxos aos filmes de arabinoxilana. Esses autores relataram que alguns lipídios são incapazes de formar uma matriz coesa e contínua, causando assim, menor ELON.

A adição da mistura de $6 \%$ de ácidos graxos resultou em aumento significativo da TR dos filmes quando comparados àqueles com adição de tipos separados de ácidos graxos (Tabela 3). Contrariamente a esse comportamento, YANG \& PAULSON [41] observaram redução da TR e da

TABELA 3 - Tensão de Ruptura (TR) e Elongação (ELON) dos filmes compostos por PEC e ácidos graxos

\begin{tabular}{rcc}
\hline \multicolumn{1}{c}{ Filmes $^{*}$} & TR $(\mathbf{M P a})^{\text {** }}$ & ELON $(\%)^{\star *}$ \\
\hline PEC/AL $6 \%$ & $54,94 \pm 1,16^{\text {cd }}$ & $1,85 \pm 0,29^{\text {fg }}$ \\
$12 \%$ & $56,82 \pm 1,97^{\mathrm{c}}$ & $3,71 \pm 0,36^{\text {bcde }}$ \\
$18 \%$ & $49,55 \pm 3,83^{\text {efg }}$ & $3,70 \pm 0,78^{\text {bcde }}$ \\
\hline PEC/AP $6 \%$ & $61,27 \pm 0,52^{\mathrm{b}}$ & $2,82 \pm 0,23^{\text {ef }}$ \\
$12 \%$ & $54,22 \pm 0,28^{\text {cd }}$ & $2,87 \pm 0,25^{\text {ef }}$ \\
$18 \%$ & $56,06 \pm 0,40^{\mathrm{c}}$ & $1,77 \pm 0,31^{9}$ \\
\hline PEC/AE $6 \%$ & $51,07 \pm 3,38^{\text {def }}$ & $3,50 \pm 0,49^{\text {cde }}$ \\
$12 \%$ & $47,34 \pm 1,35^{\text {fg }}$ & $2,96 \pm 0,36^{\text {de }}$ \\
$18 \%$ & $46,62 \pm 0,70^{\mathrm{g}}$ & $5,99 \pm 0,01^{\mathrm{a}}$ \\
\hline PEC/mis $6 \%$ & $75,89 \pm 3,06^{\mathrm{a}}$ & $4,49 \pm 0,72^{\mathrm{b}}$ \\
$12 \%$ & $62,91 \pm 3,18^{\mathrm{b}}$ & $4,07 \pm 0,84^{\text {bc }}$ \\
$18 \%$ & $51,72 \pm 2,39^{\text {de }}$ & $3,90 \pm 0,44^{\text {bcd }}$ \\
\hline
\end{tabular}

*AL=ácido láurico; $\mathrm{AP}=$ ácido palmítico; $\mathrm{AE}$ = ácido esteárico; mis=mistura dos ácidos graxos; **Média e desvio padrão de replicatas; a-g médias com letras sobrescritas distintas são significativamente diferentes, de acordo com o teste de Tukey $(\mathrm{p}<0,05)$.
ELON ao aumentarem a concentração da mistura de AE/AP nos filmes de gelana.

A adição de 12 e 18\% da mistura de ácidos graxos nos filmes de PEC promoveu redução significativa da TR em comparação aos filmes com apenas $6 \%$ da mistura.

\section{6 - Permeabilidade ao oxigênio}

Em todos os filmes preparados, observou-se que não houve diferença significativa nos resultados obtidos para permeabilidade ao oxigênio (Tabela 4). Os filmes apresentaram permeabilidade média de $11,90 \mathrm{~cm}^{3} \mu \mathrm{m} / \mathrm{m}^{2} \mathrm{~d}$. $\mathrm{kPa}$. Os resultados encontrados para os filmes estudados foram superiores aos obtidos para cloreto de polivinilideno $\left(5,1 \mathrm{~cm}^{3} \mu \mathrm{m} / \mathrm{m}^{2} \mathrm{~d} . \mathrm{kPa}\right)$ [28], próximos ao poliéster $\left(15,6 \mathrm{~cm}^{3} \mu \mathrm{m} / \mathrm{m}^{2} \mathrm{~d} . \mathrm{kPa}\right)[28]$ e inferiores ao polietileno de baixa densidade $\left(1870 \mathrm{~cm}^{3} \mu \mathrm{m} / \mathrm{m}^{2}\right.$ d. $\left.\mathrm{kPa}\right)$ [28], na mesma umidade relativa e temperatura. Em filmes de gelatina adicionados de $15 \%$ de triacetina e $10 \%$ de AE, BERTAN et al. [9] determinaram um valor de permeabilidade ao oxigênio (a $25^{\circ} \mathrm{C}, 52 \%$ UR) de $21,7 \mathrm{~cm}^{3} \mu \mathrm{m} / \mathrm{m}^{2} \mathrm{~d} . \mathrm{kPa}$.

ANKER, STADING \& HERMANSSON [1] atribuíram a baixa permeabilidade ao oxigênio encontrada em filmes à base de proteína do soro do leite à densa estrutura protéica. Uma rede fechada de proteínas aumenta o número de obstáculos que, conseqüentemente, dificulta a passagem de moléculas de oxigênio. No caso da matriz filmogênica de PEC, a hidrofilicidade da mesma pode ter contribuído para a redução da passagem das moléculas apolares do oxigênio.

TABELA 4 - Permeabilidade ao oxigênio dos filmes de pectina (PEC) adicionados de ácidos graxos

\begin{tabular}{cc}
\hline Filmes $^{*}$ & ${\text { Permeabilidade ao } \mathbf{O}_{2}\left(\mathbf{c m}^{3} \mu \mathbf{m} / \mathbf{m}^{2} \mathbf{d . k P a}\right)^{\star *}}^{*}$ PEC/AL 6\% \\
PEC/AP 6\% & $9,98 \pm 1,55^{\mathrm{a}}$ \\
PEC/AE 6\% & $10,89 \pm 1,33^{\mathrm{a}}$ \\
PEC/mis 6\% & $11,49 \pm 0,38^{\mathrm{a}}$ \\
\hline
\end{tabular}

*AL=ácido láurico; $\mathrm{AP}=$ ácido palmítico; $\mathrm{AE}=$ ácido esteárico; mis=mistura dos ácidos graxos; ** Média e desvio padrão de replicatas; ${ }^{\text {a }}$ médias com letras sobrescritas distintas são significativamente diferentes, de acordo com o teste de Tukey $(\mathrm{p}<0,05)$.

\section{7 - Opacidade dos filmes}

O filme de PVC é comumente utilizado como embalagem para diversos produtos [10] sendo, portanto, interessante comparar se os filmes em estudo foram mais transparentes ou não que o mesmo.

O filme de PEC adicionado de 6\% de AP apresentou-se 49,4\% mais opaco que o filme de PVC (Figura 2), ou seja, o mais opaco dentre os filmes selecionados para a análise. RHIM et al. [33] também obtiveram filmes compostos de isolado protéico de soja e AP com opacidade elevada, sendo que a aparência dos mesmos, quando adicionada de 30 ou $40 \%$ de AP, assemelhava-se ao aspecto de cera. YANG \& PAULSON [41] observaram aumento na opacidade dos filmes à base de gelana proporcional à concentração da mistura AE/AP adicionada, revelando assim que a adição 
de lipídio a um filme o torna mais opaco, com coloração esbranquiçada. Filmes elaborados a partir de isolado protéico do soro do leite sem adição de cera candelila apresentaram maior transparência, sendo que aqueles adicionados desta cera apresentaram-se opacos [24].

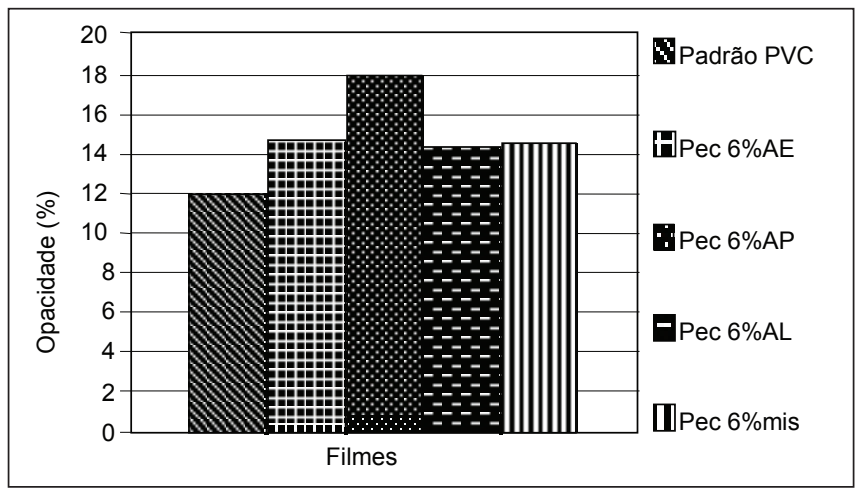

FIGURA 2 - Opacidade dos filmes (PVC=policloreto de vinila; $\mathrm{Pec}=$ pectina; $\mathrm{AE}=$ Ác. Esteárico; $\mathrm{AP}=\mathrm{A} c$. Palmítico; $\mathrm{AL}=\mathrm{A} c$. Láurico; mis=mistura (1/1/1 p/p/p dos ácidos $)$

\section{8 - Microscopia eletrônica}

Os lipídios representados pelas estruturas arredondadas na Figura $3(a, b, c, d)$ não se incorporaram homogeneamente à matriz filmogênica, provavelmente devido à hidrofilicidade acentuada da pectina, originan- do, assim, uma estrutura irregular. YANG \& PAULSON [41] também observaram estrutura irregular dos filmes de gelana adicionados da mistura de ácidos esteárico e palmítico. FAKHOURI, BATISTA \& GROSSO [15], entretanto, observaram que o AL estava fortemente ligado à matriz filmogênica de gelatina quando a morfologia do filme foi observada por MEV.

TANADA-PALMU, FAKHOURI \& GROSSO [36], ao investigarem a morfologia dos filmes à base de derivados de celulose, observaram uma organização descontínua da matriz filmogênica, o que, segundo os autores, poderia ser a justificativa da menor resistência mecânica observada nos ensaios realizados com esses filmes. CALLEGARIN et al. [11] observaram que o arranjo morfológico das cadeias de ácidos graxos em relação aos polímeros afetava as propriedades funcionais de barreira dos filmes contendo ácidos graxos na formulação. A não incorporação, microscopicamente observada, dos ácidos graxos à matriz filmogênica de PEC provavelmente foi o fator responsável pela formação da estrutura descontínua, deixando mais exposta a matriz de PEC e facilitando o aumento da PVA. Por outro lado, essa exposição pode ter sido responsável por reduzir a passagem do oxigênio pelos filmes, uma vez que os gases apresentam caráter apolar e assim tiveram pouca afinidade pela matriz polissacarídica.

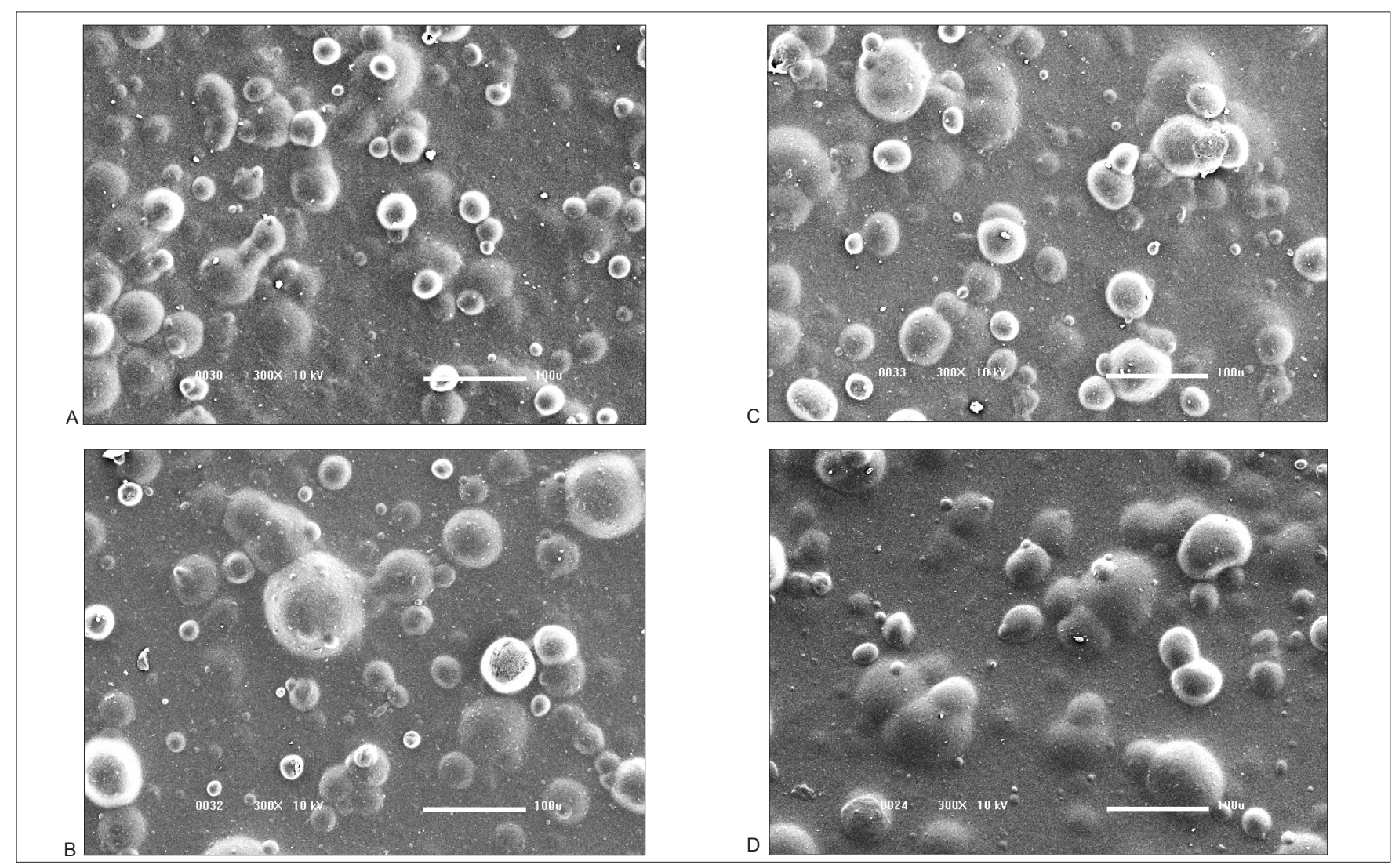

FIGURA 3 - Micrografias obtidas através de microscopia eletrônica de varredura (MEV) dos filmes: a, pectina com 6\% de ácido láurico; b, pectina com $6 \%$ de ácido palmítico; c, pectina com 6\% de ácido esteárico; d, pectina com 6\% da mistura (1:1:1) dos ácidos graxos. A barra indicativa de aumento corresponde a $100 \mu \mathrm{m}$. 


\section{4 - CONCLUSÕES}

A microscopia eletrônica de varredura mostrou que os ácidos graxos adicionados aos filmes de PEC foram incapazes de formar uma matriz coesa e contínua devido à alta hidrofilicidade da matriz. Por esse mesmo motivo, a PVA em geral aumentou com o aumento da quantidade de ácido graxo. Os diferentes comportamentos observados para as propriedades mecânicas (TR e ELON) provavelmente decorreram da desestruturação da matriz filmogênica com a adição crescente dos diferentes ácidos graxos. A utilização da mistura de ácidos graxos na preparação dos filmes aumentou a tensão na ruptura e a elongação, porém não apresentou decréscimo na PVA em relação aos filmes produzidos com a adição dos ácidos graxos individualmente.

A opacidade dos filmes de PEC adicionados de ácidos graxos foi maior que a dos filmes de PVC, o que pode ser um fator limitante na característica visual durante a aplicação dos filmes em um produto alimentício.

A alta solubilidade encontrada para os filmes pode ser uma alternativa para a aplicação dos mesmos em produtos que necessitem de hidratação prévia ao consumo, ou mesmo na cobertura de sementes agrícolas que necessitem de rápida germinação no campo ou como carreadores de aditivos necessários ao crescimento das mesmas.

\section{5 - REFERÊNCIAS BIBLIOGRÁFICAS}

[1] ANKER, M.; STADING, M.; HERMANSSON, A. Relationship between the microstructure and the mechanical and barrier properties of whey protein films. Journal of Agricultural and Food Chemistry, v. 48, n. 9, p. 3806-3816, 2000.

[2] ANKER, M.; STADING, M.; HERMANSSON, A. Aging of whey protein films and the effect on mechanical and barrier properties. Journal of Agricultural and Food Chemistry, v. 49, n. 2, p. 989-995, 2001.

[3] ASTM. Standard test methods for gas transmission rate of plastic film and sheeting. Method D 3985-81. In: Annual Book of ASTM Standards. American Society for Testing and Materials, Conshohocken, PA, 1980.

[4] ASTM. Standard test methods of water vapor transmission of materials. In: Annual Book of ASTM Standards, American Society for Testing and Materials, Philadelphia, E 96-95, 1995a.

[5] ASTM. Tensile properties of thin plastic sheeting. In: Annual Book of ASTM Standards, American Society for Testing and Materials, Philadelphia, D 882, 1995b.

[6] AXELOS, M.A.V.; THIBAULT, J.F. The chemistry of low methyl pectin. In: WALTER, R. H. (Eds.). The Chemistry and Technology of Pectin. New York: Academic Press, 1991, ch. 6, p. 109-118.

[7] AYRANCI, E.; TUNC, S. The effect of fatty acid content on water vapour and carbon dioxide transmissions of cellulose-based edible films. Food Chemistry, v. 72, n. 2, p. 231-236, 2001.

[8] BAUDET, L.; PERES, W. Recobrimento de sementes. Seed News, n. 1, p. 20-23, 2004.

[9] BERTAN, L.C.; TANADA-PALMU, P.S.; SIANI, A.C.;
GROSSO, C. Effect of fatty acids and Brazilian elemi on composite films based on gelatin. Food Hydrocolloids, v. 19, n. 1, p. 73-82, 2005.

[10] BRISTON, J.H. Plastic Films, 3rd ed. New York: John Wiley \& Sons, 1988, p. 349-407.

[11] CALLEGARIN, F.; GALLO, J.Q.; DEBEAUFORT, F.; VOILLEY, A. Lipids and biopackaging. Journal of the American Oil Chemists Society, v. 74, n. 10, p. 1183-1192, 1997.

[12] CHEN, H. Functional properties and applications of edible films made of milk proteins. Journal of Dairy Science, v. 78, n. 11, p. 2563-2583, 1995.

[13] CHEN, S.; NUSSINOVITCH, A. The role of xanthan gum in traditional coatings of easy peelers. Food Hydrocolloids, v. 14, n. 4, p. 319-326, 2000.

[14] DADLANI, M.; SHENOY, V.V.; SESHU, D. V. Seed coating to improve stand establishment in rice. Seed Science and Technology, v. 20, n. 5, p. 307-313, 1992.

[15] FAKHOURI, F.M.; BATISTA, J.A.; GROSSO, C. Efeito de coberturas comestíveis aplicadas em goiabas in natura (Psidium Guajava L.) I. Desenvolvimento e caracterização de filmes comestíveis de gelatina, triacetina e ácidos graxos. Brazilian Journal of Food Technology, v. 6, n. 2, p. 301-308, 2003.

[16] FISHMAN, M.L.; COFFIN, D.R. Mechanical, microstructural and solubility properties of pectin/poly (vinyl alcohol) blends. Carbohydrate Polymers, v. 35, n. 3-4, p. 195-203, 1998.

[17] GALIETTA, G.; DI GIOIA, L.; GUILBERT, S.; CUQ, B. Mechanical and thermomechanical properties of films based on whey proteins as affected by plasticizer and crosslinking agents. Journal of Dairy Science, v. 81, n. 12, p. 3123-3130, 1998.

[18] GALLO, J.A.Q.; DEBEAUFORT, F.; CALLEGARIN, F.; VOILLEY, A. Lipid hydrophobicity, physical state and distribution effects on the properties of emulsion-based edible films. Journal of Membrane Science, v. 180, n. 1, p. 37-46, 2000.

[19] GONTARD, N.; DUCHEZ, C.; CUQ, J.L.; GUILBERT, S. Edible composite films of wheat gluten and lipids: water vapor permeability and other physical properties. International Journal of Food Science and Technology, v. 29, n. 1, p. 39-50, 1994.

[20] GUILBERT, S.; BIQUET, B. Les films et enrobage comestibles. In: BUREAU, G.; MULTON, J. L. L'Emballage des Denrées Alimentaires de Grande Consommation, Technique et documentation. France, Lavoisier, Apria, 1989, p. 320.

[21] HUNTERLAB. The Color Management Company, Universal Software, version 3.2. Reston, 1997.

[22] KAMPER, S.L.; FENNEMA, O. Water vapor permeability of an edible, fatty acid, bilayer film. Journal of Food Science, v. 49, n. 6, p. 1482-1485, 1984.

[23] KESTER, J.J.; FENNEMA, O.R. Edible films and coatings: a review. Food Technology, v. 42, p. 47-59, 1986.

[24] KIM, S.J.; USTUNOL, Z. Sensory attributes of whey protein isolate and candelilla wax emulsion edible films. Journal of Food Science, v. 66, n. 6, p. 909$911,2001$.

[25] MARINIELLO, L.; DI PIERRO, P.; ESPOSITO, C.; SORRENTINO, A.; MASI, P.; RAFÉALE, P. Preparation and mechanical properties of edible pectin-soy 
flour films obtained in the absence or presence of transglutaminase. Journal of Biotechnology, v. 102, n. 2, p. 191-198, 2003.

[26] MENEZES, N.L. A Semente e sua Germinação. Disponível em: <www.ufsm.br/sementes/textos/semeger. shtml>. Acesso em: 11 ago. 2003.

[27] McHUGH, T.H.; KROCHTA, J.M. Milk-protein-based edible films and coating. Food Technology, v. 48, n. 1, p. 97-103, 1994a.

[28] McHUGH, T.H.; KROCHTA, J.M. Sorbitol- vs. glycerolplasticized whey protein edible films: integrated oxygen permeability and tensile property evaluation. Journal of Agricultural and Food Chemistry, v. 42, n. 4, p. 841-845, 1994b.

[29] MORILLON, V.; DEBEAUFORT, F.; BOND, G.; CAPELLE, M.; VOLLEY, A. Factors affecting the moisture permeability of lipid-based edible films: a review. Critical Reviews in Food Science and Nutrition, v. 42, n. 1, p. 67-89, 2002.

[30] NISPEROS-CARRIEDO, M.O. Edible coatings and films based on polysaccharides. In: KROCHTA, J.M.; BALDWIN, E.A.; NISPEROS-CARRIEDO, M.O. (Eds.). Edible Coatings and Films to Improve Food Quality, Publishing Company, Lancaster, Pennsylvania, 1994, ch. 11, p. 305-335.

[31] PEREZ-GAGO, M.B.; KROCHTA, J.M. Denaturation time and temperature effects on solubility, tensile properties, and oxygen permeability of whey protein edible films. Journal of Food Science, v. 66, n. 5, p. 705-710, 2001.

[32] PÉROVAL, C.; DEBEAUFORT, F.; DESPRÉ, D.; VOILLEY, A. Edible arabinoxylan-based films. 1. Effects of lipid type on water vapor permeability, film structure and other physical characteristics. Journal of Agricultural and Food Chemistry, v. 50, n. 14, p. 3977-3983, 2002.

[33] RHIM, J.W.; WU, Y.; WELLER, C.L.; SCHNEPE, M. Physical characteristics of emulsified soy protein-fatty acid composite films. Sciences des Aliments, v. 19, n. 1, p. 57-71, 1999.

[34] SHELLHAMMER, T.H.; KROCHTA, J.M. Edible coatings and film barriers. In: Gunstone, F. D.; Padley, F. B. (Eds.). Lipids Technologies and Applications, 1997, ch. 17, p. 453-479.

[35] SHIH, F.F. Edible films from rice protein concentrate and pullulan. Cereal Chemistry, v. 73, n. 3, p. 406409, 1996.

[36] TANADA-PALMU, P.S.; FAKHOURI, F.M.; GROSSO, C.R.F. Filmes biodegradáveis. Biotecnologia, Ciência \& Desenvolvimento, v. 5, n. 26, p. 12-17, 2002.

[37] TANADA-PALMU, P.S.; GROSSO, C.R.F. Wheat gluten composite and bilayer edible films: effect of lipid addition. Res. Adv. in Agricultural \& Food Chemistry, v. 3, p. 53-60, 2002.

[38] THAKUR, B.R.; SINGH, R.K.; HANDA, A.K. Chemistry and uses of pectin - a review. Critical Reviews in Food Science and Nutrition, v. 37, n. 1, p. 47-73, 1997.

[39] WONG, D.W.S.; GASTINEAU, F.A.; GREGORSKI, K.S.; TILLIN, S.J.; PAVLATH, A.E. Chitosan-lipid films: microstructure and surface energy. Journal of Agricultural and Food Chemistry, v. 40, n. 4, p. 540-544, 1992.

[40] XIE, L.; HETTIARACHCHY, N.S.; JU, Z.Y.; MEULLENET, J.; WANG, H.; SLAVIK, M.F.; JANES, M.E. Edible film coating to minimize eggshell breakage and reduce post-wash bacterial contamination measured by dye penetration in eggs. Journal of Food Science, v. 67, n. 1, p. 280-284, 2002.

[41] YANG, L.; PAULSON, A.T. Effects of lipids on mechanical and moisture barrier properties of edible gellan film. Food Research International, v. 33, n. 7, p. 571-578, 2000.

\section{6 - AGRADECIMENTOS}

Ao CNPq pela concessão da bolsa de mestrado a Juliana A. Batista. 